\title{
Design and Simulation Analysis of Micro-Porous Structure in Infiltration- Type Self-Lubrication Composites Matrix
}

\author{
HAN Ying ${ }^{1, a}$ \\ ${ }^{1}$ School of Mechanical Engineering, Shandong Yingcai University, Ji'nan, 250104, China
}

\begin{abstract}
Metal ceramic preforms were fabricated by vacuum sintering method in this work. Ti-Fe-Cr-W-Mo-V powder was used as the basic material, $\mathrm{TiH} 2$ and $\mathrm{CaCO} 3$ were used as the composite pore-forming material and $\mathrm{Al} 2 \mathrm{O} 3$ was used as dispersal particles. The microstructure and the worn surface morphology of the preforms and the composites were analyzed using scanning electron microscope (SEM) and energy dispersive spectrometer (EDS). The experimental results showed that when the micro-pore shapes are circular and quadrilateral respectively, with the increasing load, the Mises equivalent stress distribution generated by the single cell model is quite different, but it has symmetry, and the maximum stress appears around the interpenetrating micro-pore. Using FeCrWMoV alloy powder as the metal phase and $\mathrm{TiC}$ powder as the ceramic phase, the micro-porous matrix was prepared by powder metallurgy sintering with the addition of a certain volume fraction of compound pore-making agent.
\end{abstract}

\section{Introduction}

The new type of infiltration self-lubrication composites is prepared by using bionic tribology. Under vacuum pressure, the melt solid lubricant is immersed in the micro- pore matrix. Under the action of high temperature and friction heat, the solid lubricant is precipitated out to the friction interface along the micro-pore structure[1]. The material has good mechanical properties and selflubricating properties under special working conditions such as high temperature and high pressure, and is widely used in aerospace, electronic machinery and other industries.

The main function of the micro-pore matrix is to bear the load, which affects the mechanical properties and various properties of composite materials[2,3]. How to control the micro-pore structure of the matrix, so that it can store enough lubricant to meet the requirements of lubrication performance[4], and at the same time, it has enough strength to meet the requirements of mechanical performance is the key of this paper.

\section{Finite element simulation}

\subsection{Pore shape}

The micro-pore structure of the infiltration selflubrication composites matrix is complex, which mainly depends on the powder particles and the production process. Micro-pore structure characteristics affect the mechanical properties of the self-lubricating composites, which is the key to determine the number of infiltrated solid lubricant, the uniformity of lubricant distribution and whether the lubrication film can be formed at the friction interface[5]. Therefore, the micro-pore shape is an important structural characteristic parameter of porous matrix.

The micro-pore matrix was prepared by powder metallurgy sintering, and its internal structure was very complex. In order to facilitate the analysis, the micropore structure is assumed as follows: the micro-pore is uniformly distributed; the micro-pore size is equal; the wall thickness is uniform and isotropic. Taking the regular quadrilateral as the basic cell, the structural sections of different micro-pore shapes are shown in figure1. (a)

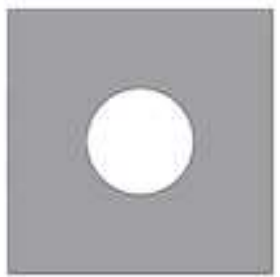

(b)

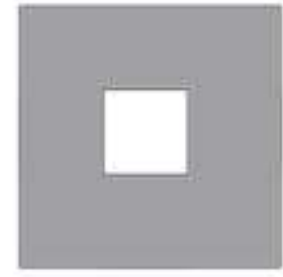

Figure 1. Micropore section diagram: (a) circular (b)quadrangle

\subsection{Finite element simulation}

In the process of preparing micro-pore matrix, the size and shape of micro-pore were not the same due to the mutual influence of the size of powder particle, the proportion of pore-forming agent and sintering process parameters. However, from a macroscopic point of view, the micro-pore structure was still arranged periodically and repeatedly. The Mises equivalent stress and strain were analyzed by applying uniformly distributed displacement load to a three-dimensional single cell model in space.

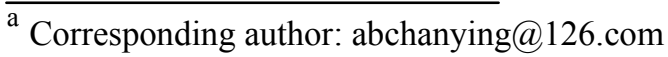


Figure 2 is the equivalent stress distribution cloud map produced by the cellular model with a porosity of $20 \%$. It can be seen from the figure that different micro-pore structure models produce different degrees of deformation and different stress values, but the maximum stress appears around the interpenetrating micro-pore. With the increase of external load, the value of equivalent stress increased gradually. When the loading is the same, the Mises equivalent stress produced by the circular microcellular model is the smallest, followed by the quadrangle.
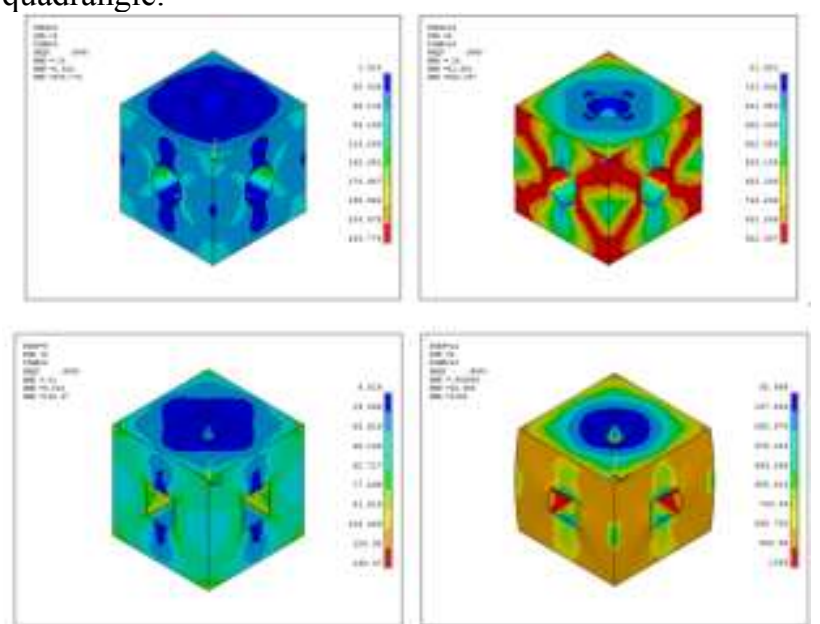

Figure 2. Cloud map of equivalent stress distribution generated by the single cell model

\section{Experimental procedure}

\subsection{Preparation of sample}

The matrix powder was mixed with $80 \%$ (volume fraction) in $\mathrm{Ti}-\mathrm{Fe}-\mathrm{Cr}-\mathrm{W}-\mathrm{Mo}-\mathrm{V}$ (the chemical composition as: $20 \% \mathrm{Ti}, 4 \% \mathrm{Cr}, 6 \% \mathrm{~W}, 5 \% \mathrm{Mo}, 3 \% \mathrm{~V}$, Fe in balance) alloy powders (particle size of 15 to $25 \mu \mathrm{m}$ ) and $20 \%$ (volume fraction) $\mathrm{Al}_{2} \mathrm{O}_{3}$ ceramic powder (particle size of 20 to $25 \mu \mathrm{m}$ ). And $40 \%$ (volume fraction)of $\mathrm{TiH}_{2}$ and $60 \%$ (volume fraction) of $\mathrm{CaCO}_{3}$ were added as complex pore-forming agent. It was ball-milled for $4 \mathrm{~h}$, and then die-pressed into cylindrical specimens of $\varnothing 12 \mathrm{~mm} \times 16 \mathrm{~mm}$ under a $600 \mathrm{MPa}$ of compaction pressure. After compaction, sample was vacuum sintered under 0.1 to $0.01 \mathrm{~Pa}$ and sintering temperature was $1200^{\circ} \mathrm{C}$ to $1300^{\circ} \mathrm{C}$.

\subsection{Experimental method}

The liquid static equilibrium method is used to test the density, the porosity and the volume of infiltration lubricant of the preform. The micro hardness and crushing strength of samples were tested using HVS-type micro hardness tester and YE-600 type hydraulic testing machine respectively. Friction and wear properties of the composites were investigated using a high temperature XP-5 pin-on-disk wear tester. The pin in the form of 12 $\mathrm{mm}$ diameter and $15 \mathrm{~mm}$ length was rounded to hemispherical type of $10 \mathrm{~mm}$ diameter at one end and surface roughness of $0.2 \mu \mathrm{m}$ to $0.8 \mu \mathrm{m}$. The disk was made of Ti-Al ceramic coating materials with geometric size of $55 \mathrm{~mm} \times 5 \mathrm{~mm}$. The hardness of the disk was HRC 62 to 67 and surface roughness of $0.2 \mu \mathrm{m}$. The friction and wear tester were conducted at temperature of $600^{\circ} \mathrm{C}$ and sliding speed of $0.139 \mathrm{~m} / \mathrm{s}$. The samples microstructures and worn surface morphology were characterized using scanning electron microscope (SEM) equipped with an energy dispersive spectroscope (EDS).

\section{Results and discussion}

\subsection{Microstructure}

Figure 3 is matrix powder (metal and ceramic phase volume fraction ratio of $80: 20$ ) particle size is $55-75$ microns, compound pore-forming agent content is $7 \%$, at $1230{ }^{\circ} \mathrm{C}$ sintering, thermal insulation, after $60 \mathrm{~min}$ sintered sample pore structure characteristics of different cross section. As can be seen from figure 3(a), the micropore distribution on the surface of the sample is relatively uniform, the pore size is basically the same, and the micro-pore shape is mainly round, square and irregular, etc. As can be seen from figure 3(b), the internal structure of the sample is intersected into a network, similar to the structure of human sweat glands. Fig. 3(c) and (d) are enlarged SEM images with square and circular micropore shapes respectively. In the process of actual preparation, the matrix of self-lubricating composite material with thick wall cell structure was obtained by taking metal ceramics as the raw material and using compound hole making agent through secondary hole making. Because of the different sintering process parameters such as sintering temperature, heating speed and heat preservation time, various pore shapes will be formed simultaneously in the sintering matrix, and the porosity percentage of various pore shapes will be different.
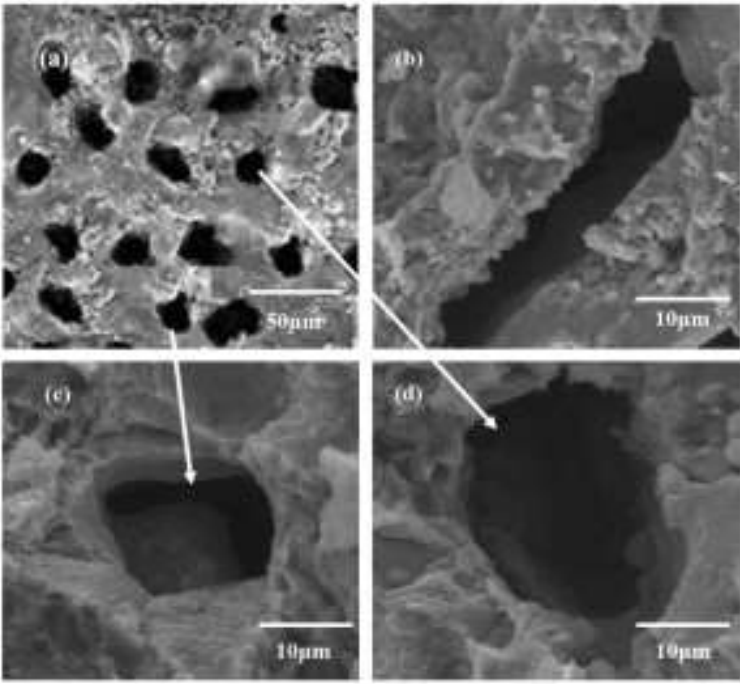

Figure 3. Micro-pore structure of sintered sample:

(a) surface; (b) axial section; (c) square hole; (d) round hole

\subsection{The determination of sintering process parameters}

Fig.4 shows the change curve of metal ceramic sintered body about micro hardness and crushing strength. With the increase of sintering temperature, the micro hardness and crushing strength of preform was improved. When the temperature was more than $1230^{\circ} \mathrm{C}$, the curve became flat. This situation is not in conformity with the regular 
pattern that intensity was dropped according to the index law with the increase of porosity [6]. It was suggested that the preform have corresponding porosity under a certain sintering temperature. With the increase of sintering temperature, the preform tended to be dense and the porosity was decreased. The diffusion speed was accelerated and the activity of powder was enhanced with the increasing of sintering temperature [7, 8]. In consideration of the requirements of pore structure and wear resistance about the preform, the advisable sintering temperature is about $1230^{\circ} \mathrm{C}$.

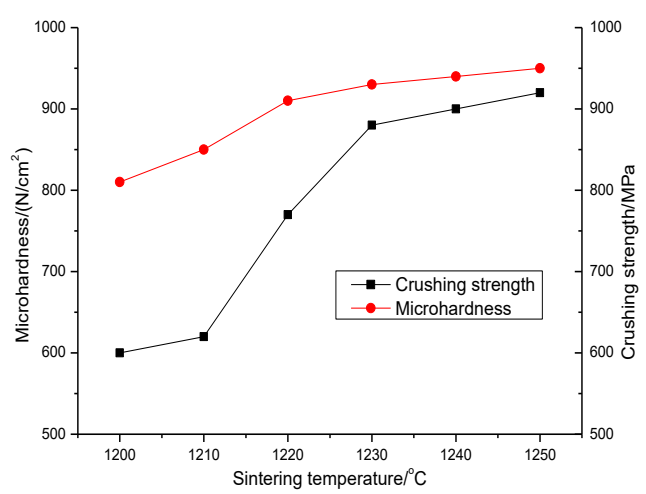

Figure 4. Influence of sintering temperature on micro hardness and crushing strength of the preform

\section{Conclusion}

When the micro-pore shapes are circular and quadrilateral respectively, with the increasing load, the Mises equivalent stress distribution generated by the single cell model is quite different, but it has symmetry, and the maximum stress appears around the interpenetrating micro-pore. Using FeCrWMoV alloy powder as the metal phase and $\mathrm{TiC}$ powder as the ceramic phase, the microporous matrix was prepared by powder metallurgy sintering with the addition of a certain volume fraction of compound pore-making agent. The micro-pore shape is regular (mainly round or square), and the pores are evenly distributed and interspersed into networks 。

\section{References}

1. J. W. Qiu, Y. Liu, Y. B. Liu: Material \& Design. Vol. 33(2012)

2. X. L. Sun, Y. Liu, Y. Lu: Powder Metallurgy Technology. Vol. 19(2001)

3. Z. M. Liu: Wear. Vol. 262(2007)

4. J. M. Xue, C.X. Sun: Journal of East China University of Science and Technology, Vol. 28(2002)

5. Y. J. Wang, Z .M .Liu: Chinese Journal of Mechanical Engineering.Vol.42.(2006)

6. H. D. Ding: The Transaction of Nonferrous Metals Society of China, Vol. 11(2001)

7. H.Chang, J. Binner, R. Higginson, P. Myers, P. Webb, G.King: Materials Science and Engineering A. Vol. 529(2011)
8. Z. F. Xu, H. Yu: Chinese journal of nonferrous metals, Vol. 169(2006) 